\title{
Política Cultural em tempos de democracia \\ a Era Lula
}

\author{
Lia Calabre ${ }^{1}$
}

\section{Resumo}

A proposta deste artigo é a de fazer um balanço das políticas culturais durante a gestão do presidente Luiz Inácio Lula da Silva (2003-2010). Alguns parâmetros contemporâneos de política cultural democrática e participativa começaram a ser colocados em prática, no Brasil nesse período. Inicialmente será apresentada uma rápida reconstituição das políticas culturais no Brasil, com ênfase especial no período posterior à criação do Ministério da Cultura (1985). Seguida de uma análise das gestões dos ministros Gilberto Gil e Juca Ferreira.

\section{Palavras-chave}

Políticas culturais, Governo Lula, Ministério da Cultura.

Recebido em 24 de outubro de 2013

Aprovado em 3 de dezembro de 2013

CALABRE, Lia. Política Cultural em tempos de democracia: a Era Lula. Revista do Instituto de Estudos Brasileiros, Brasil, n. 58, p.137-156, jun. 2014.

DOI: http://dx.doi.org/10.11606/issn.2316-901X.v0i58p137-156

I Fundação Casa de Rui Barbosa (FCRB, Rio de Janeiro, RJ, Brasil). 


\title{
Cultural Policy in Democratic Times The Lula Age
}

\section{Lia Calabre}

\begin{abstract}
The purpose of this article is to summarize the cultural policies during the administration of President Luiz Inácio Lula da Silva (2003-2010). Some contemporary parameters of democratic and participatory cultural policy began to be put into practice in Brazil during this period. It will initially be presented a rapid reconstitution of cultural policies in Brazil, with special emphasis on the period after the establishment of the Ministry of Culture (1985), followed by an analysis of the Ministers Gilberto Gil and Juca Ferreira managements.
\end{abstract}

Keywords

Cultural policies; Lula Administration, Ministry of Culture. 
Daí que a política cultural deste ministério, a política cultural do governo Lula, a partir deste momento, deste instante, passa a ser vista como parte do projeto geral de construção de uma nova hegemonia em nosso país. Como parte do projeto geral de construção de uma nação realmente democrática, plural e tolerante. Como parte e essência da construção de um Brasil de todos.

(Ministro Gilberto Gil, discurso de posse em 2 de janeiro de 2003) 


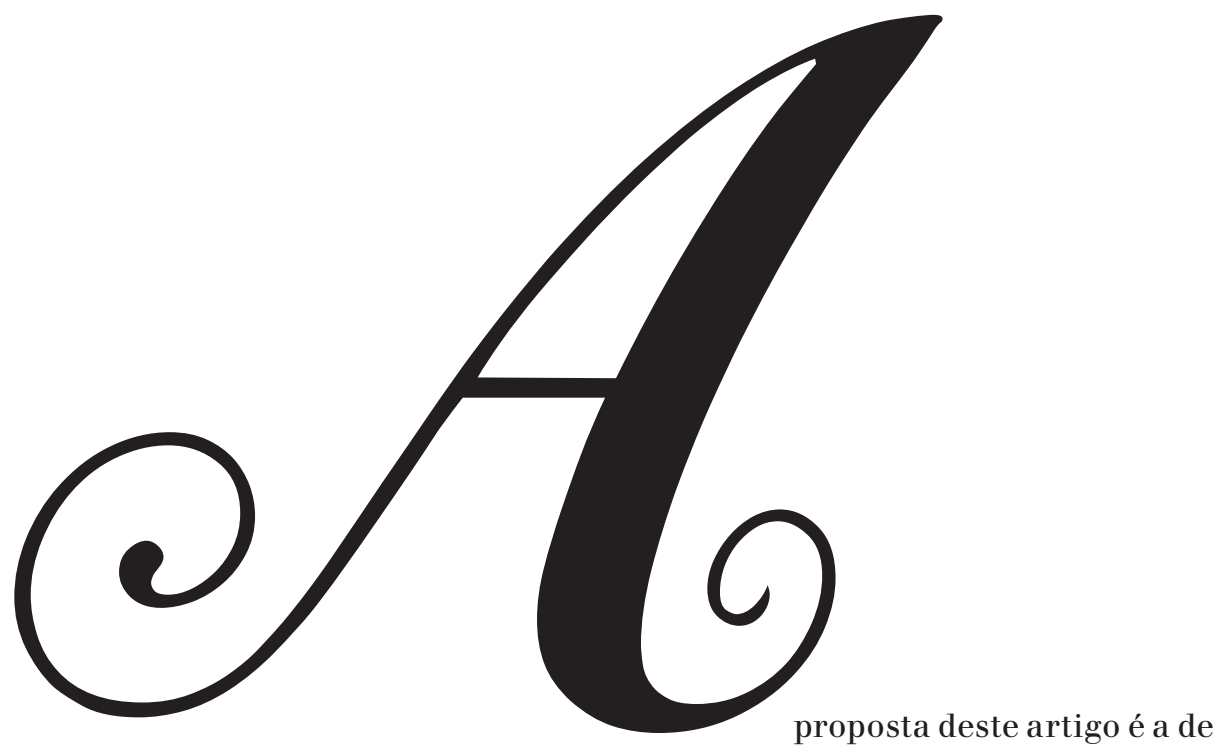

fazer um balanço das políticas culturais durante a gestão do presidente Luiz Inácio Lula da Silva (2003-2010). No Brasil, definir política cultural como um campo no qual devem atuar o poder público e os mais diversos setores da sociedade civil, há alguns anos, era falar de um modelo ideal, quase utópico. A história das políticas culturais no Brasil, até a chegada do século XXI, teve seus pontos altos, contraditoriamente, nos períodos de governos autoritários. Tal conjuntura não atende aos preceitos do conceito de políticas culturais que foi construído, internacionalmente, a partir da década de 1970, tendo por base ações conjuntas e partilha de poder decisório entre Estado e sociedade civil. Esses parâmetros contemporâneos de uma política cultural democrática e participativa começam a ser colocados em prática, no Brasil, no início do governo do presidente Lula, em 2003. Foram oito anos de gestão, com muitos acertos e também com muitos problemas, mas que, sem dúvida, marcaram positivamente a história das políticas culturais no Brasil. Pois, como afirma a filósofa Marilena Chaui, em uma sociedade:

[...] polarizada por carências profundas e privilégios cristalizados, propor uma política cultural supõe decisões mais amplas, definição clara de prioridades, planejamento rigoroso dos recursos. [...] Numa perspectiva democrática, as prioridades são claras; trata-se de garantir direitos existentes, criar novos direitos e desmontar privilégios. $^{2}$

2 CHAUI, Marilena. Cidadania cultural: O direito à cultura. São Paulo: Editora Fundação Perseu Abramo, 20o6. p.65. 
Com o objetivo de analisar o processo de transformação ocorrido entre os anos de 2003 e 2010, inicialmente será apresentada uma rápida reconstituição das políticas culturais no Brasil, com ênfase especial no período que se segue à criação do Ministério da Cultura (1985). Tal estratégia nos permitirá fazer, a seguir, uma melhor avaliação das ações, programas e políticas implementadas no governo do presidente Lula, no qual estiveram no comando da pasta da Cultura o ministro Gilberto Gil (2003-2008) e o ministro Juca Ferreira (2008-2010).

\section{Desvio no tempo}

A maioria dos estudiosos sobre políticas culturais no Brasil concorda que os dois principais momentos, nos quais é possível identificar a elaboração e a implementação de políticas culturais, foram o governo de Getúlio Vargas, em especial na gestão do Ministro Gustavo Capanema (1934-1945), e ditadura civil-militar, mais especialmente na década de $1970^{3}$.

Ao longo da década de 1970, a área da cultura foi sendo fortalecida com a criação de novas instituições, como a Funarte. A área da cultura ainda estava vinculada à educação, compondo o Ministério da Educação e Cultura (MEC) ${ }^{4}$, mas já havia alcançado um lugar de destaque dentro da pasta e ganho uma secretaria específica, o que permitia ao Secretário de Cultura mais autonomia. Em 1985, foi criado o Ministério da Cultura. Era um projeto de Tancredo Neves (que faleceu) e foi colocado em prática por José Sarney, o primeiro presidente civil depois de mais de duas décadas de ditadura. A reformulação, que para alguns poucos ${ }^{5}$ parecia ser uma possibilidade de fortalecimento institucional, para a área se mostrou desastrosa, pois ao se separar da educação, a cultura deixou de acessar e partilhar muitos dos recursos da área, ou seja, perdeu tanto em

3 Para mais informações, ver: CALABRE, Lia. Políticas culturais no Brasil: dos anos 1930 ao século XXI. Rio de Janeiro: FGV, 2oog. Ver também RUBIM, Antônio A. C. Políticas Culturais no Brasil: tristes tradições, enormes desafios. In: ; BARBALHO, A. (orgs.). Políticas Culturais no Brasil. Salvador: Edufba, p. 11-36, 2007; e BARBALHO, A. Políticas Culturais no Brasil: identidade e diversidade sem diferença. ed. cit., p. 37-6o.

4. Que guarda o C de cultura ainda hoje, apesar de ser exclusivo da Educação.

5 A avaliação dos técnicos da área é que essa era uma decisão precipitada, se a cultura havia obtido um destaque dentro do Ministério da Educação e Cultura, dificilmente tal quadro se manteria com um ministério exclusivo. Ver: BOTELHO, Isaura. Romance de Formação: Funarte e Política Cultural - 1976-199o. Rio de Janeiro: Edições Casa de Rui Barbosa, 2000. p. 215. 
orçamento, como em status político. Em 1981, Aloísio Magalhães, que era o Secretário de Cultura, declarou em uma entrevista que

no momento seria prematuro pensar na criação de um Ministério da Cultura porque, agora, ele seria forçosamente um ministério fraco, não só do ponto de vista financeiro mas do próprio ponto de vista conceitual. ${ }^{6}$

O Ministério da Cultura (MinC) foi criado com um orçamento insignificante, que mal mantinha funcionando a estrutura interna e as instituições a ele vinculadas ficaram com o novo ministério alguns conselhos (Conselhos Federal de Cultural, Conselhos Nacional de Direito Autoral e o Conselho Nacional de Cinema); autarquias (Empresa Brasileira de Filmes S/A - Embrafilme) e fundações ligadas à área da cultura (Fundação Nacional de Arte - Funarte, Fundação Nacional Pró-Memória, Fundação Casa de Rui Barbosa e Fundação Joaquim Nabuco ${ }^{7}$ ).

Dentro dessa conjuntura de escassez de recursos, presenciamos a criação da primeira lei de incentivo fiscal, a Lei $n^{\circ} 7.505$, de 2 de julho de 1986, que ficou conhecida como Lei Sarney. Os mecanismos de funcionamento da lei sofreram intensas críticas durante seu curto período de vigência, mas não podemos negar que o fluxo de recursos gerados por ela contribuiu para dinamizar o campo da produção cultural, em especial nos grandes centros urbanos. O Ministério foi extinto logo no início de 1990, já no governo Collor, sendo substituído por uma secretaria, e os órgãos a ele vinculados, na maioria, foram agrupados em dois grandes institutos: o Instituto Brasileiro de Arte e Cultura (IBAC) e o Instituto Brasileiro de Patrimônio Cultural (IBPC); e a Lei Sarney extinta.

Em novembro de 1991, a Lei ${ }^{\circ}$ 8.313, reformula e reedita o uso de recursos incentivados para a cultura. Tem início a era da Lei Rouanet, que sofreu algumas regulamentações posteriores e que, 22 anos depois de sua criação, encontra-se em plena vigência.

Durante o governo do presidente Fernando Henrique Cardoso, o uso de Lei Rouanet foi consolidado. O governo federal investiu largamente no slogan "Cultura é um bom negócio". Foram oito anos de governo de inspiração neoliberal, trabalhando pela construção de um Estado mínimo e repassando para a iniciativa privada, através da Lei Rouanet, o poder de decisão sobre o financiamento e apoio da produção cultural

6 Magalhães, Aloisio. E Triunfo? A questão dos bens culturais no Brasil. Rio de Janeiro: Nova Fronteira/Fundação Roberto Marinho, 1977. p.148-149.

7 Que logo foi transferida novamente para o Ministério da Educação. 
do país. Foi com esse quadro, de um Ministério da Cultura voltado para a administração dos mecanismos da Lei de Incentivo, que o governo Lula se deparou.

\section{Os primeiros anos da gestão Lula}

A problemática do redimensionamento do lugar da cultura dentro da área das políticas públicas era uma questão que já estava presente no documento "A imaginação a serviço do Brasil" parte integrante do programa de governo da campanha presidencial de Lula em 2002 que tinha como subtítulo: "Programa de políticas públicas de cultura". O Programa dialogava com documentos e estudos internacionais nos quais a cultura é considerada como um direito básico, propondo que as políticas culturais devem estar voltadas para o desenvolvimento e o fortalecimento da democracia.

Para ocupar a pasta da Cultura, o presidente Lula convidou o cantor e compositor Gilberto Gil. O desafio que estava inicialmente posto, segundo o próprio ministro em seu discurso de posse, era o de “tirar o Ministério da Cultura da distância em que ele se encontra, hoje, do dia a dia dos brasileiros" e fazendo com que ele passe estar "[...] presente em todos os cantos recantos de nosso país". ${ }^{8}$

Logo de início é proposta uma reformulação na estrutura do próprio MinC. As secretarias passam a ser organizadas sob a lógica da implementação de políticas, substituindo a estrutura anterior que estava voltada para as atividades e finalidades da lei de incentivo. Assim, ao invés de uma secretaria da música e artes cênicas, do livro, etc., foram criadas as secretarias de: Articulação Institucional; Políticas Culturais; Programas e Projetos Culturais (que mudou de nome algumas vezes); Identidade e Diversidade Cultural; Fomento e Incentivo Culturais (que cuida da Lei de Incentivo), sendo mantida a de Audiovisual: A reformulação ministerial foi aprovada em 12 de agosto de 2003, através do Decreto $n^{\circ}$ 4.805. A ideia era de que as atividades finalísticas tais como o patrimônio, as artes, o livro fossem tratadas pelas instituições vinculadas ao MinC com atuação nas respectivas áreas (como o Iphan, a Funarte e a Biblioteca Nacional). Aloisio Magalhães, um dos nomes que

8 Discurso de Gilberto Gil. In: ALMEIDA, Armando et al (orgs.). Cultura pela palavra: coletânea de artigos, discursos e entrevistas dos ministros da Cultura (20032010) Gilberto Gil e Juca Ferreira. Rio de Janeiro: Versal, 2013. p. 239. 
se destacaram na área da gestão da cultura, no início da década de 1980, já nos alertava para o fato de que:

Parece paradoxal. Mas, para conseguirmos melhorar nossa situação, é preciso aumentar a complexidade do sistema. Diante da carência que nós temos muito grande, de métodos, de recursos humanos, de recursos financeiros, é preciso crescer e, crescendo, aumentando a complexidade disso, ter, como compensação, uma sólida frente, uma presença muito mais maciça e muito mais constante, na conquista de espaço, nas conquistas de espaços pertinentes e da competência do bem cultural. ${ }^{9}$

Um ponto em pauta, logo no início da gestão do ministro Gil, era o da reformulação da Lei de Incentivo, que deveria ser substituída por uma mais adequada à nova realidade nacional. Para discutir e buscar subsídios para a reformulação da Lei Rouanet foram realizados os seminários “Cultura para todos", que percorreu parte do país, sendo realizados nos seguintes estados: Rio Grande do Sul, São Paulo, Rio de Janeiro, Minas Gerais, Pernambuco e Pará. Integravam as atividades dos seminários encontros setorizados com secretários de cultura estaduais e municipais; investidores privados e fundações, investidores estatais; e pessoas físicas (artistas e produtores em especial). Os participantes tinham como tarefa responder a duas questões: 1) Quais são os principais entraves para o acesso ao financiamento público federal da cultura (Lei Rouanet e Lei do Audiovisual)?; e 2) Quais os mecanismos que devem ser adotados para garantir a transparência e a descentralização do financiamento público da cultura? Os seminários ocorrreram em 2003 e a primeira e grande contribuição deles foi a de abrir canais de diálogos entre o MinC e os mais variados atores sociais que atuam no campo da cultura. O Ministério, nessa primeira série de encontros, foi a localidades nas quais nunca havia estado, criou uma rede de novos interlocutores, além de optar por um sistema de escuta pública como o caminho para construção de novas políticas culturais. Alem disso, a partir da análise das respostas obtidas nas consultas, a avaliação geral foi a de que o mecanismo necessitava ser reformulado sim, porém, havia uma série de problemas que poderiam ser solucionados, a curto prazo, através de portarias ministeriais, da divulgação mais sistemática da lei e da capacitação de produtores e de gestores nas mais diversas regiões do país - fato que gerou a elaboração

9 MagalHãeS, Aloisio. Boletim do Conselho Federal de Cultura. Brasília, Ano 11, n. 42, 1981. p. 43 
de programas de capacitação realizados pela Secretaria de Fomento à Cultura. Outra constatação feita a partir dos diálogos foi a de que, apesar da várias críticas existentes ${ }^{10}$, o mecanismo cumpria um papel fundamental em determinadas áreas da produção cultural e regiões do país, apontando para a necessidade de que o projeto de reformulação fosse realizado de maneira que não paralisasse os processos em curso ${ }^{11}$.

Na esfera da construção e elaboração de novas políticas, a Secretaria de Políticas Culturais (SPC) iniciou um importante diálogo com os órgãos de pesquisa federais, em especial com o Instituto Brasileiro de Geografia e Estatística (IBGE) e o Instituto de Pesquisas Econômicas Aplicadas (Ipea), no sentido de propor a produção e sistematização das informações sobre o campo da cultura. As informações deveriam permitir um conhecimento mais efetivo sobre a realidade e a potência do campo da cultura, base fundamental para um processo de elaboração de novas políticas. Também foi retomada a discussão sobre a importância da mensuração da contribuição da cultura na formação do produto interno bruto, como estratégia de fortalecimento político do próprio campo. Com essa finalidade, o MinC vem trabalhando, desde então, com o IBGE na direção da construção de uma Conta Satélite da Cultura ${ }^{12}$.

É interessante ressaltar que a preocupação com a produção e sistematização de informações sobre as próprias ações do MinC eram praticamente inexistentes até então. A base de informações dos projetos da Lei Rouanet, por exemplo, era pouco mais que um programa de cadastro de processos, cujos relatórios gerados formavam uma série histórica parcial, pois as formas de registro de informações tiveram sua lógica alterada algumas vezes, não havendo uma preocupação mais efetiva com a questão. A discussão sobre a necessidade da produção de informações sobre o campo da cultura, em geral, e da gestão pública, em especial, para a criação de programas e políticas culturais na esfera pública não é nova. Várias tentativas de levar a questão adiante, promovendo ações efetivas,

10 As críticas são referentes ao caráter historicamente concentrador do uso da lei de incentivo, seja por proponentes do eixo Rio-São Paulo (nas capitais desses estados), seja pelo fato de que um pequeno grupo de proponentes e áreas artísticas específicas detém parte significativa dos recursos.

11 Para mais informações ver: CALABRE, Lia. Políticas culturais no Brasil do século XXI: cenários e desafios. In: COSTA, Frederico Lustosa da (org.). Política e gestão cultural: perspectiva Brasil e França. Salvador: Edufba, 201z. p. 4o.

12 A conta satélite de cultura é uma sistematização das informações sobre as atividades econômicas relacionadas aos bens e serviços culturais. A partir das informações coletadas poderá ser elaborado um cálculo sobre o peso da área da cultura na constituição do Produto Interno Bruto (PIB). O IBGE é o órgão responsável pela construção das contas satélites das diversas áreas (como a da saúde, por exemplo). 
sofreram processos de descontinuidade e de baixo grau de investimento. Essa foi, por exemplo, uma das problemáticas frequentemente abordadas pelo Conselho Federal de Cultura (1966-1990). Já naquele momento havia a consciência de que para se alcançar a eficiência e a eficácia na elaboração de políticas para a área da cultura - como para qualquer outra área de política pública - é primordial a existência de informações sobre o campo. Existiam propostas de realização de pesquisas e de formação de sistemas setoriais. Essa problemática também esteve presente na gestão do ministro Celso Furtado em 1986, e, fazendo uma digressão temporal, podemos mesmo remontar ao período da gestão de Mário de Andrade, na década de 1930, no Departamento de Cultura da Cidade de São Paulo, onde a questão da produção de informações estava presente no discurso e na prática do órgão.

A partir de 2003, vários estudos e análises sobre as diferentes áreas de atuação do Ministério foram produzidas e publicadas pelo Ipea por solicitação da Secretaria de Políticas Culturais (SPC) ${ }^{13}$. Também nesse momento que foram retomados vários esforços no sentido de mapear e compreender o campo da economia da cultura. Os primeiros esforços nesse sentido haviam sido envidados na gestão do economista e ministro da Cultura Celso Furtado, quando foram encomendados à Fundação João Pinheiro estudos sobre algo que era uma grande novidade: a economia da cultura.

Ao longo dos anos de 2004 e de $2005^{14}$, foram realizados vários encontros entre membros do Ministério da Cultura e do IBGE, dos quais resultaram diversos produtos e ações, como promoção de seminários e reuniões com técnicos de outros países (em especial da França e da Colômbia), a formação de um grupo de trabalho no IBGE para extrair das pesquisas existentes informações, que sistematizadas, passam a compor as publicações do Sistema de Informações e Indicadores Culturais (do IBGE). Um dos trabalhos que se destacou nessa parceria entre o MinC e o IBGE foi a publicação de um suplemento de cultura na Pesquisa de Informações Básicas Municipais (Munic), que foi a campo em 2005 e teve seu lançamento em 2006. A Munic é uma pesquisa anual realizada pelo IBGE desde a década de 1990, que abrange todos os municípios brasileiros, contendo grupos de módulos diferenciados de questões sobre a gestão pública municipal a cada ano e são repetidas periodicamente.

13 Nos anos seguintes, o Ipea produziu análises e pesquisas para as diversas secretarias do Ministério. Parte desse trabalho pode ser encontrados nos volumes 2 e 3, dos Cadernos de Políticas Culturais, publicados pelo MinC e organizados por Frederico A. Barbosa da Silva (pesquisador do Ipea responsável pelas análises).

14. O Ministério da Cultura assinou um acordo de parceria com o IBGE em 17 de dezembro de 2004 . 
A pesquisa já havia levantado algumas informações sobre a área da cultura como, por exemplo, os dados sobre a existência de equipamentos culturais e meios de comunicação, que constam nas publicações de 1999, 2001 e 2005.

O suplemento de cultura da Munic foi composto por 14 blocos de questões, levantando informações variadas da gestão pública desde a estrutura do órgão gestor, passando por instrumentos de gestão (leis, conselhos, etc.), mapeando ações, projetos, atividades, equipamentos, entre outras. Enfim, a publicação apresenta uma gama variada de informações fundamentais tanto para a elaboração de políticas de alcance nacional, quanto para o início da estruturação do Sistema Nacional de Cultura, que estava a cargo da Secretaria de Articulação Institucional (SAI).

Antes de passarmos para as ações da SAI, gostaria de reforçar a importância da realização da pesquisa pelo IBGE, tanto para a esfera da gestão pública de cultura, quanto para a ampliação dos estudos acadêmicos sobre a área. As informações contidas nas publicações têm sido largamente utilizadas em trabalhos acadêmicos. O suplemento nos revela, por exemplo, ainda que de maneira indireta, a matriz autoritária e a visão unidirecional que formavam a concepção que parte significativa dos gestores municipais possuía sobre políticas culturais, no momento em que foi a campo. Havia no suplemento uma questão específica sobre a existência, ou não, de políticas culturais locais para a qual 57,9\% dos municípios respondeu positivamente. Entretanto, quando se percorre alguns dos outros itens da pesquisa, tais como o da existência de leis, conselhos, fundos, ações, etc., verifica-se que os índices apresentados são extremamente baixos, fato que leva aos pesquisadores e estudiosos perguntarem-se sobre qual será o conceito de políticas culturais com o qual tais gestores municipais dialogaram efetivamente. É muito provável que a noção de política cultural vigente não fosse nem mesmo aquela que constava do próprio instrumento de coleta de informações, que nos informa que:

Política cultural é a ação do poder público ancorada em operações, princípios e procedimentos administrativos e orçamentários. Esta política é orientada para melhorar a qualidade de vida da população através de atividades culturais, artísticas, sociais e recreativas, proporcionando à mesma o acesso aos bens culturais. Tratase de uma ação voltada para todo o município e não para alguns segmentos da sociedade. ${ }^{15}$

15 IBGE. Pesquisa de Informações Básicas Municipais - Gestão Pública - Suplemento de Cultura 2006. Rio de Janeiro: IBGE, 2007. Formulário de coleta. 
As informações levantadas pelo suplemento de cultura do IBGE reforçaram a percepção corrente sobre a necessidade do aprimoramento da formação profissional e da estruturação do campo da gestão pública de cultura. Pode-se inferir, até então, uma significativa ausência de preocupação, por parte de muitos dos que ocupam os cargos da gestão pública de cultura, na elaboração de pesquisas e diagnósticos sobre a área. A formação desse novo profissional foi um desafio primordial que estava posto para a Secretaria de Articulação Institucional, que tinha a construção de um Sistema Nacional de Cultura (SNC) como principal meta. O desenho do SNC foi concebido com base em alguns elementos fundamentais, dentre os quais destaco dois: as conferências e os planos de cultura.

Ao longo do ano de 2005, o Ministério da Cultura organizou as diversas etapas preparatórias da $1^{\text {a }}$ Conferência Nacional de Cultura que ocorreu em dezembro do mesmo ano. Formalmente, ela também foi uma das etapas do processo de elaboração do Plano Nacional de Cultura ${ }^{16}$. Foi a primeira vez que o governo reuniu os mais variados setores da sociedade para realizar uma ampla discussão sobre políticas culturais. A Conferência é um mecanismo participativo, de consulta pública e, nesse caso, tinha como principal atribuição recolher sugestões para a elaboração das diretrizes básicas de um plano nacional na área da cultura.

O momento preparatório da Conferência teve por base dois tipos específicos de ação: a realização dos seminários setoriais "Construindo o Plano Nacional de Cultura" (organizado diretamente pelo MinC) e as conferências municipais, estaduais e intermunicipais. Com o objetivo de subsidiar as discussões e a elaboração de propostas de diretrizes para o Plano Nacional de Cultura, foram indicados cinco eixos de discussão: 1) Gestão Pública e Cultura; 2) Cultura é Direito e Cidadania; 3) Economia da Cultura; 4) Patrimônio Cultural; e 5) Comunicação é Cultura. Os seminários setoriais foram organizados com a parceria da Comissão de Educação e Cultura da Câmara dos Vereadores, com o apoio do chamado Sistema S e das administrações municipais das cinco cidades que foram escolhidas para sediá-los ${ }^{17}$. A organização das conferências municipais e estaduais é uma atribuição dos governos locais. Foram realizadas 19 conferências estaduais e 1.197 conferências municipais. O Ministério

16 O Plano Nacional de Cultura foi instituído através da Emenda Constitucional $n^{\circ} 4^{8}$ de $1^{0}$ de agosto de 2005 .

17 Os parceiros do MinC na realização dos seminários setoriais foram: o Sistema CNI/Senai/Sesi, o Sistema CNC/Sesc/Senac, a OEI e a Unesco, as prefeituras e alguns dos governos estaduais onde os seminários foram realizados. As cidades que sediaram foram Londrina, Juiz de Fora, Petrolina, Juazeiro, Manaus e Cuiabá. 
estimou que o processo de realização da I Conferência Nacional de Cultura envolveu 53 mil pessoas em todo o país ${ }^{18}$.

O Plano Nacional de Cultura (PNC), segundo o previsto na Emenda Constitucional que o instituiu, deve conduzir à: I) defesa e valorização do patrimônio cultural brasileiro; II) produção, promoção e difusão de bens culturais; III) formação de pessoal qualificado para a gestão da cultura em suas múltiplas dimensões; IV) democratização do acesso aos bens da cultura; e V) valorização da diversidade étnica e regional. Ele é o documento base a partir do qual o governo federal deverá pautar, nos próximos dez anos, o direcionamento das ações públicas de cultura. Um plano é uma espécie de "carta de navegação" e, como tal, algumas vezes necessita ser ajustado ao "longo da viagem". Para isso, há a previsão de uma etapa de avaliação intermediária sobre o cumprimento das metas ao final dos primeiros quatro anos. A construção do PNC foi um processo de longa duração, que ocupou parte dos dois mandatos do Presidente Lula e deve ser analisado como um grande exercício de democracia participativa. Em dezembro de 2010, o PNC foi finalmente aprovado, sendo composto por cinco capítulos, nos quais se distribuem 14 diretrizes, 36 estratégias e 275 ações com vigência decenal. A execução do PNC é acompanhada a partir de 53 metas estabelecidas com base no conjunto das diretrizes, estratégias e ações previstas no documento.

Neste contexto, temos ainda o início dos esforços para a construção legal do Sistema Nacional de Cultura, com o objetivo de criar um arcabouço institucional mínimo que colabore para a estruturação e consolidação de políticas culturais democráticas, corroborando para a formação de uma sociedade mais justa e menos desigual. A ideia do sistema (seguindo o desenho de outros sistemas setoriais já existentes) é fornecer uma maior institucionalidade para a área, com a exigência da existência de um órgão gestor de cultura, por exemplo, e, ao mesmo tempo, buscando facilitar o diálogo e a execução de ações compartilhadas entre os diferentes níveis de governo, através de repasses entre fundos de cultura. Há ainda o estímulo efetivo para a adoção de uma prática de gestão pública mais democrática e participativa na medida que estabelece a realização de conferências e a criação de um conselho de política cultural paritário e deliberativo, como elementos fundamentais para a participação no Sistema ${ }^{19}$.

18 Para mais informações, ver: BRASIL, Ministério da Cultura. $I^{a}$ Conferência Nacional de Cultura 2005/20o6. Estado e sociedade construindo políticas públicas de cultura. Brasília: MinC/Secretaria de Articulação Institucional do Ministério da Cultura, 2007 .

19 A lei do Sistema Nacional de Cultura somente foi aprovada em 2012. 
Ainda dentro da análise desses primeiros anos de governo, devemos apontar as inovações de duas outras secretarias, que definiram como seu público alvo segmentos da população que, em sua maioria, não haviam sido objeto de ações, programas e políticas culturais durante as gestões anteriores. A primeira delas foi a Secretaria de Identidade e Diversidade Cultural (SID), que colocou em prática uma série de ações variadas para as culturas populares, ciganas, indígenas, idosos, LGBT e saúde, enfim, apoiou projetos variados a partir de mecanismos diferenciados de fomento. É também importante salientar que a SID e a Secretaria de Políticas Culturais cumpriram um papel fundamental, junto ao Ministério das Relações Exteriores, no processo de construção da Convenção da Diversidade Cultural da Unesco. O Brasil teve uma atuação destacada durante todo o processo de construção e aprovação do documento internacional. Trabalho que foi desdobrado internamente tendo como principal estratégia a realização de seminários por todo o país para divulgar os princípios da Convenção.

Um programa que adquiriu uma dimensão destacada logo nos primeiros tempos do governo de Lula foi o Programa Cultura Viva, criado em 2004 por meio da Portaria Ministerial $n^{\circ} 156$, sob a responsabilidade da Secretaria de Programas e Projetos Culturais (SPPC) posteriormente transformada em Secretaria da Cidadania Cultural (SCC). O Programa tem como principais objetivos: ampliar e garantir acesso aos meios de fruição, produção e difusão cultural; potencializar energias sociais e culturais, dando vazão à dinâmica própria das comunidades, entre outros. A base do Programa são os Pontos de Cultura, mas há outras ações que o compõe. Em 2007, quando o Ipea realizou a primeira pesquisa sobre o programa, havia 526 pontos de cultura conveniados em todas as regiões do país (em 2010 esse número já ultrapassava as 2.500 unidades). Os Pontos de Cultura estão hoje presentes em todos os estados do país e, em sua maioria, através dos convênios entre o governo federal e os governos estaduais. Segundo Frederico Barbosa:

No Brasil existem movimentos sociais e culturais expressivos. Há espaços alternativos, mercados culturais localizados e dinamismos que em nada se assemelham aos das grandes indústrias culturais. Essa dinâmica cultural passou a ser reconhecida nas políticas culturais brasileiras de forma significativa nos últimos 
anos e o Programa Arte, Cultura e Cidadania - Cultura Viva teve importante papel no reconhecimento do Brasil profundo. ${ }^{20}$

Também na direção da ampliação do espectro de atores atendidos pelas políticas públicas de cultura, foram construídos novos projetos e programas pela Secretaria do Audiovisual (SAv). O incentivo à criação de cineclubes e espaços alternativos de exibição de conteúdo audiovisual, a distribuição de conteúdos para esses novos espaços e o fomento de festivais contribuem para minimizar o problema da escassez de salas de cinema por todo o país. A SAv, através de parcerias, criou projetos inovadores como o "Revelando os Brasis", um projeto dirigido aos moradores de municípios brasileiros com até 20 mil habitantes, que tem como principal objetivo promover processos de inclusão e formação audiovisuais. A cada edição se realiza um concurso que seleciona 40 histórias (reais ou ficcionais) que deverão ser transformadas em vídeos digitais com até 15 minutos de duração. A ideia do projeto nasceu na Secretaria do Audiovisual, em 2004, integrando um conjunto maior de ações que visavam à democratização do acesso aos meios de produção audiovisual, foi executado através de parceiras com o apoio do $\mathrm{MinC}^{21}$. Esse conjunto de projetos, ações, programas e políticas que foram apresentados teve sua criação logo na primeira metade da gestão Lula e não constitui uma lista exaustiva do que foi proposto e realizado, mas consideramos uma amostra significativa que permite uma compreensão do conjunto. O processo que vai da elaboração à implementação efetiva dos mesmos é longo, não linear e, muitas vezes, enfrenta resistências e problemas de natureza diversa. Muitas das inovações propostas só obtiveram efetividade no segundo mandato do presidente Lula e outras ainda ultrapassaram esse período.

\section{Algumas reflexões sobre a conjuntura}

Ao sair do campo da análise das ações individualizadas, é interessante lançar um olhar mais abrangente sobre o contexto em estudo, a partir de uma estratégia analítica que também tenha por base algumas questões mais conceituais (ou de princípios) que impactaram no processo

20 IPEA. Cultura Viva: as práticas de pontos e pontões. Ipea/Coordenação de Cultura. Brasília: Ipea, 2011. p. 17.

21 Mais informações ver: CALABRE, Lia. Revelando os Brasis: o projeto. Políticas Culturais em Revista, Salvador, v. 4, n.2, jan. 2012. Disponível em: < http://www.portalseer .ufba.br/index.php/pculturais/article/view/5598>. Acesso em: 23 maio 2014. 
efetivo de implementação política. A primeira delas está assentada no fato de que os programas e ações foram criados tendo na base teórica um conceito de cultura ampliado, que busca compreender e ativar elementos do que se chamou de a "tridimensionalidade da cultura", com as dimensões simbólica, cidadã e econômica, definidas pelo MinC, como:

A dimensão simbólica é aquela do "cultivo" (na raiz da palavra cultura) das infinitas possibilidades de criação expressas nas práticas sociais, nos modos de vida e nas visões do mundo. [...] A dimensão cidadã consiste no reconhecimento do acesso à cultura como um direito, bem como da sua importância para a qualidade de vida e a autoestima de cada um. [...] Na dimensão econômica, inscreve-se o potencial da cultura como vetor de desenvolvimento. Trata-se de dar asas a uma importante fonte geradora de trabalho e renda, que tem muito a contribuir para o crescimento da economia brasileira. ${ }^{22}$

As iniciativas que foram construídas ao longo dos oito anos, aqui em estudo, mantinham um estreito diálogo com a noção de tridimensionalidade da cultura. Ainda que possamos afirmar que os objetivos propostos para as respectivas dimensões não tenham sido completamente alcançados em muitos dos programas, estas estiveram todo o tempo presentes no campo discursivo. O Ministério fez uso do "capital simbólico" (no sentido atribuído por Bourdieu) contido na noção de tridimensionalidade, realizando ações que resultaram em efetivos avanços no campo da estruturação de políticas culturais em bases mais democráticas, participativas, abrangentes e cidadãs. Entram para a pauta de discussão política de uma maneira mais efetiva as problemáticas dos direitos culturais, da cidadania cultural e da economia da cultura.

Uma segunda questão que se destaca no cenário analisado é a de que as discussões presentes no processo de elaboração das ações tinham como princípio pensar as políticas públicas de cultura com base em novos desenhos de gestão. Dentro de um novo modelo de gestão democrática, temos a chamada administração pública societal que, segundo Ana Paula Paes de Paula, tem por principal característica a organização dos serviços de maneira descentralizada e participativa, com desenhos de gestão partilhada fundamentada na manutenção das responsabilidades. Para alguns estudiosos, tal sistema foi sendo gradativamente aplicado

22 BRASIL, Ministério da Cultura. Cultura em três dimensões. Material informativo: as políticas do Ministério da Cultura de 2003 a 2010. Brasília: MinC, 2010. p. 8. 
no país nas diversas áreas do governo ao longo do período da gestão Lula. Na visão da autora, esse modelo de gestão não possuiu fórmulas pré-determinadas, pois são construídas a partir das realidades locais, informadas por uma nova filosofia, se afastando dos modelos burocráticos ou gerenciais ${ }^{23}$. Para a efetiva implementação e fortalecimento desse novo modelo, o governo necessitaria criar, ou ampliar, canais e instrumentos que propiciem uma participação mais efetiva da sociedade no processo decisório, tais como a realização de fóruns, de conferências, de plebiscitos, ou a criação de câmaras e conselhos, ou seja, um modelo teórico bem próximo do que foi aplicado ao longo das gestões de Gil e Juca no Ministério da Cultura.

Uma terceira concepção teórica abordada de forma inovadora, ou diferenciada, foi a da diversidade cultural. Como afirma Hamilton Faria "vivemos um momento de expressão da diversidade, vozes antes ausentes do mundo público passam a se manifestar e desejam um lugar ao sol no sistema decisório". ${ }^{24}$ Uma das pautas do conjunto das discussões de políticas públicas de cultura, nos dois mandatos do presidente Lula, foi a da criação de instrumentos que garantam os direitos culturais, a promoção e a proteção da diversidade cultural. Entre os compromissos assumidos pelos países signatários da Convenção da Diversidade, e o Brasil é um deles, estão os de "proteger e promover a diversidade das expressões culturais"; "criar condições para que as culturas floresçam e interajam livremente em benefício mútuo"; "encorajar o diálogo entre culturas". Tais compromissos colocam na ordem do dia uma questão fundamental: o conhecimento das práticas culturais do país por parte dos gestores públicos (fato que não se restringe aos resultados obtidos através da coleta de dados estatísticos, por exemplo). Em verdade: “como considerar realizada a inclusão social se os valores, comportamentos, modos de vida, imaginários, raízes, práticas e heranças culturais, manifestações, fabulações e celebrações da maioria da população são desconhecidos das gestões?"25, questionam os pesquisadores Altair Moreira e Hamilton Faria ao tratarem das questões dos governos municipais, que, teoricamente, deveriam ser os detentores de um conhecimento mais aprofundado da realidade sob sua responsabilidade administrativa.

23 PAULA, Ana Paula Paes de. Por uma nova gestão pública. Rio de Janeiro: FGV, 2005. p. 153-171.

24. FARIA, Hamilton. Conselhos de cultura: novos e antigos desafios da cidadania cultural. In: RUBIM, A. Albino; TAIANE, Fernandes; RUBIM, Iuri (orgs.). Politicas culturais, democracia e conselhos de cultura. Salvador: Edufba, 2010.p. 280.

25 MOREIRA, Altair José; FARIA, Hamilton. Cultura e governança: um olhar transversal de futuro para o município. In: . et al (orgs.). Você quer um bom conselho? Conselhos municipais de cultura e cidadania cultural. São Paulo: Instituto Pólis, 2005. p. 12 
Além das questões teóricas e conceituais acima elencadas, uma outra problemática que merece destaque é a territorialização das políticas públicas. Em um país de dimensões continentais como o Brasil, de imensa diversidade geográfica e cultural, sem dúvida, é impensável a sustentação de projetos e programas uniformes direcionados a todo o país, ou mesmo às macrorregiões. Tal afirmativa que é válida para as mais diversas áreas da política pública, no caso da cultura merece um destaque ainda mais especial. Os cuidados com a implementação de projetos padronizados nacionalmente devem ser redobrados, pois existem questões e problemas que devem ser atacados nacionalmente, mas não necessariamente através de ações uniformes. A preocupação com a distribuição desigual de recursos financeiros e humanos pelo conjunto do país também esteve na pauta das ações do MinC nas gestões Gil e Juca; nas conferências nacionais de cultura, as questões regionais ficaram mais evidentes.

Ao traçarmos um mapa do acesso aos recursos financeiros, materiais e até mesmo humanos no campo da cultura no país, vemos reproduzido um quadro de desigualdades muito similar ao de outras áreas, com uma forte concentração de recursos no sudeste, mas, em especial, em algumas regiões dos grandes centros urbanos em detrimento de outras, ou seja, há um complexo emaranhado de centros e periferias de centros. Por isso é tão importante que o processo de territorialização das políticas na área da cultura dialogue com outras políticas setoriais, sem perder suas especificidades, que esteja atento a uma série de variáveis já mapeadas por outras áreas e que, se levadas em consideração, podem contribuir para uma alteração no mapa das desigualdades vigente no país.

Dialogando com o Programa de Aceleração do Crescimento (PAC) do governo federal como um todo, o MinC lançou o programa Mais Cultura que foi apresentado, em algumas oportunidades, como o embrião do Sistema Nacional de Cultura, na medida que estabelecia convênios e parcerias com os governos estaduais e municipais para repasse de recursos em um processo de estadualização dos programas e das políticas. O Programa era gerido pela Secretaria de Articulação Institucional, criando uma espécie de coordenação central de uma série de programas, ações e projetos implementados por outras secretarias. Entretanto, é importante ressaltar que os projetos viabilizados através do programa Mais Cultura, como afirma Frederico Barbosa, "apenas se conectam de forma significativa com a ideia de sistema, como exercício do sistema, e não como arcabouço global, com o ideal normativo de arquitetura institucional". ${ }^{26}$

26 SILVA, Frederico A. Barbosa. O Programa Mais Cultura, o Fundo Nacional de Cultura e o Sistema Nacional de Cultura. In: . et al (orgs.) As politicas públicas 


\section{Reflexões complementares}

Buscando compor um quadro sintético da gestão do MinC entre 2003 e 2010, podemos afirmar que os primeiros quatro anos foram marcados por um conjunto de proposições de programas, políticas e ações que alçaram o Ministério a um patamar de importância e destaque na cena política nacional que não havia sido alcançado até então. O órgão ganhou espaço na mídia nacional, sem dúvida muito alicerçado no capital simbólico do Ministro Gilberto Gil. Foram feitas proposições inovadoras e provocacões criativas. Por outro lado, esse conjunto de propostas inovadoras veio igualmente acompanhado por um conjunto de desafios a serem vencidos para que o primeiro pudesse ganhar efetividade. A maior parte delas vinha acompanhada pela necessidade de alterações na cultura política vigente, de reformulação de alguns instrumentos de gestão, e mesmo, de alguns princípios de aplicação das políticas. O ritmo da implementação das inovações foi sendo freado ao longo da segunda metade do período analisado. Algumas ações estruturantes como a implantação do Sistema Nacional de Cultura, a aprovação do Plano Nacional de Cultura, a reformulação da lei de direitos autorais, a reformulação da lei de incentivo à cultura e a construção do Sistema Nacional de Informações e Indicadores Culturais eram alguns dos pilares de sustentação de um novo projeto político para a área. Destes, somente o Plano Nacional de Cultura se tornou realidade dentro da gestão, ainda que somente no final de 2010.

Podemos afirmar que entre 2007 e 2010, falando de maneira mais metafórica, uma série de novas portas foram abertas sem que as anteriores fossem fechadas, ou melhor, sem que as inovações propostas tivessem obtido algum grau de efetividade. Isto significa dizer que novos intentos surgiam, novos campos de diálogo eram abertos, novas parcerias foram sugeridas, ampliando as dificuldades de efetivação já evidentes. Sem dúvida o Ministério ousou, ampliou a complexidade da pasta, alargou seu campo de ação, intensificou os debates sobre a cultura colocando-a no campo das políticas públicas, mas várias lacunas ficaram igualmente abertas. O presidente Lula, em diversas oportunidades, expressou a importância da pasta da cultura, mas o Ministério não conseguiu alcançar o simbólico 1\% do orçamento para a cultura.

A perda do que se costuma denominar "tempo político", no qual os debates estão mais intensos e a problemática em questão sustenta um capital político significativo, coloca em risco a efetividade dos projetos

e suas narrativas: o estranho caso entre o Mais Cultura e o Sistema Nacional de Cultura. Brasília: Ipea, 2011. p. 217. 
em seus princípios originais. No caso das ações promovidas pelo MinC, uma série de novos atores políticos foram ativados ao longo dos dois mandatos, criando a expectativa da efetividade da implantação de novos modelos de gestão das políticas culturais. Uma ruptura dos processos em curso coloca em risco a credibilidade e efetividade do caráter participativo e democrático que foi sendo proposto. Ainda que não possamos trabalhar com o que poderia ter sido, não podemos deixar de lamentar a demora na concretização de propostas, políticas, programas e ações que surgiram nos primeiros anos da gestão Gil. Várias destas foram herdadas pela gestão que teve início no governo da presidenta Dilma sem que fossem acompanhadas pelos princípios inspiradores e justificativos das mesmas

\section{Sobre a autora:}

\section{Lia Calabre}

Pesquisadora e chefe do setor de políticas culturais da Fundação Casa de Rui Barbosa, desde 2012. Doutora em história pela Universidade Federal Fluminense (UFF). Autora de livros e artigos sobre políticas culturais, tais como Politicas Culturais no Brasil: dos anos 1930 ao século XXI (Ed. FGV, 2009) e Políticas Culturais no Brasil: história e contemporaneidade (BNB, 2010). E-mail: liacalabre@rb.gov.br 